\title{
Stéréotypes du « russe » et du « français »: regards croisés
}

Stereotypes of 'Russian' and 'French': Exchanges of Viewpoints

\section{Elena L. Berezovich et Galina Kabakova}

\section{OpenEdition}

1 Journals

Édition électronique

URL : http://journals.openedition.org/res/740

DOI : $10.4000 /$ res. 740

ISSN : 2117-718X

Éditeur

Institut d'études slaves

\section{Édition imprimée}

Date de publication : 31 décembre 2015

Pagination : 389-412

ISBN : 978-2-7204-0540-2

ISSN : 0080-2557

Référence électronique

Elena L. Berezovich et Galina Kabakova, «Stéréotypes du « russe » et du «français » : regards croisés », Revue des études slaves [En ligne], LXXXVI-4 | 2015, mis en ligne le 26 mars 2018, consulté le 01 mai 2019. URL : http://journals.openedition.org/res/740; DOI : 10.4000/res.740 


\title{
STÉRÉOTYPES DU « RUSSE » ET DU « FRANÇAIS » REGARDS CROISÉS*
}

\author{
PAR \\ Elena L. BEREZOVICH \\ Université fédérale de l'Oural, Ekaterinburg \\ Galina KABAKOVA \\ Université Paris-Sorbonne, Eur-Orbem
}

La linguistique de ces deux dernières décennies a recours de plus en plus souvent à la notion de « stéréotype langagier », interprétée comme un jugement naif et constant sur le monde, fixée dans la forme interne, le sémantisme de l'entité lexicale ou dans ses rapports systémiques (voir par exemple, Bartminskij 2005 ; Ždanova 2005 ; Žernovaja 2010 ; Romaško 2009; Стереoтипы 2009 ; Stereotypy 2009 ; Amossy, Herschberg Pierrot 2011, etc.) Parmi les stéréotypes langagiers, les stéréotypes ethniques tiennent une place de choix. Dans cette étude, nous les interprétons comme des complexes de représentations naïves et constantes sur un peuple, une nation, reflet des particularités de la "xénopsychologie » populaire. Le stéréotype ethnique peut être considéré comme étalon du stéréotype en général. Dans la construction du stéréotype ethnique, les mécanismes de la stéréotypisation apparaissent de manière saillante : en dépit de la possibilité de la connaissance empirique du sujet (peuple étranger), l'orientation axiologique reposant sur l'opposition « nôtre » $v s$ « étranger » est tellement puissante qu'elle subjectivise l'image au maximum et s'éloigne considérablement du savoir rationnel (ainsi, l'étranger symboliquement peut être rapproché d'un animal ou de la force du mal).

Les stéréotypes ethniques se déclinent dans divers groupes de lexique ; on considère que les informations les plus précieuses pour la formulation et l'analyse des stéréotypes sont contenues dans les entités lexicales désignant les

\footnotetext{
*L'étude réalisée dans le cadre du programme de compétitivité de l'Université fédérale de l'Oural (20132020), groupe de recherches « Tradition langagière populaire, source de l'information historico-culturelle ». La version russe de cette étude paraîtra dans la revue « Forum anthropologique ». Nous proposons au lecteur de la Revue des études slaves une version remaniée d'un chapitre. 
traits de caractère et les spécificités du comportement des ethnies. En revanche, on trouve que le pan «matériel » de la stéréotypisation est encore sous-estimé : le vocabulaire de la cuisine nationale, des vêtements, des objets quotidiens, etc. Ces informations lexicales sont d'une grande importance car la transposition des représentations du caractère et du mode de vie nationaux sur le plan matériel permet de les transmettre de manière détournée et indirecte. Cela fournit une information objective sur le subjectif et permet de faire la lumière sur des aspects inédits des stéréotypes. Dans cet article, nous nous arrêterons uniquement sur le code matériel des ethno-stéréotypes langagiers : les stéréotypes du russe en français et du français en russe.

L'apparition de ces stéréotypes tient à l'histoire séculaire et riche en rebondissements des contacts franco-russes. Elle connaît des périodes de confrontations militaires et d'alliance politique, de refroidissement des relations entre les deux nations, de gallomanie de longue durée et de russophilie plus circonscrite dans le temps. Ces représentations culturelles et langagières de la « russité » ou de la « francité » sont rarement étudiées sur le plan comparatif, ni confrontées face à face. Nous nous proposons de procéder à une analyse contrastive, afin de mettre au jour la logique des perceptions mutuelles.

Le cœur de ces représentations, c'est-à-dire les faits linguistiques dont la forme intérieure contient une indication directe de « russité » ou de « francité », n'a pas encore fait l'objet d'une étude spécifique. Dans cette étude nous avons fait la part belle aux faits de la langue, aux contextes littéraires aussi bien du $\mathrm{XIX}^{\mathrm{e}}$ que du XXe siècle, tandis que H. Bergmann s'est penché uniquement sur le lexique (Bergmann 2012) et O. Šaova, Raymond Blanchard, Joceline Chabot et Sylvia Kasparian ont étudié les stéréotypes du russe et du français dans la presse (Шаова 2005 ; Blanchard, Chabot, Kasparian 2011). Nous avons sélectionné le lexique qui répond aux critères suivants : en russe, les dérivés des mots франиуз, Франиия et des racines inusitées et dialectales telles que храни-, -хранз-, франч-, фрянк- ; en français, les dérivés des mots Russe, Cosaque (« Cosaque » $\rightarrow$ « militaire russe » $\rightarrow$ « Russe »), Moscou, vieil. Moscovite. On prend également en considération des locutions comprenant ces vocables, comme par exemple, одеваться по-парижски [s'habiller à la parisienne] " s'habiller avec élégance, à la mode », roulette russe " jeu suicidaire ». On constate pour ces expressions un degré plus ou moins élevé de figement, mais il existe également des locutions récurrentes, des constructions nominales pour l'essentiel, où le degré de figement est plus libre : французский сыр. Il s'agit des items d'origine russe ou française : ils sont fabriqués en France, produits en Russie, etc. Par rapport à ces locutions, on retient le critère suivant : nous analysons de telles expressions si elles ont une haute fréquence et si leur sémantique est « suffisante » ${ }^{1}$ et ne nécessite pas d'explications supplémentaires puisqu'elles

1. À propos de l'usage de ce critère dans l'analyse de stéréotypes ethniques voir Plungjan, Raxilina 1996. 
évoquent chez les locuteurs une image plastique précise. Ainsi la locution франиузский сыр correspond à une représentation concrète, illustrée par le contexte suivant :

[...] дырчатые французские сыры, прельстительные, как французская любовь, прелесть которой никто, однако, не может выразить словами.

[...] les fromages français à trous, séduisants comme l'amour français, dont personne cependant ne peut exprimer le charme avec des mots.

V. Golovanov, « Comme j’aimais ma patrie », la Capitale, 1997.

On trouve également des contextes où ces « fromages français » constituent une sorte d' " emblème » alimentaire de la France:

- Однако у вас не будет здесь ни английского чая, ни итальянского прошютто, ни французских сыров, ни американских сигарет, ни шотландского виски $[\ldots]$.

- Cependant nous n'aurons ni thé anglais, ni prosciutto italien, ni fromages français, ni cigarettes américaines, ni whisky écossais.

V. Aksenov, l'île de Crimée, 1979.

Ce sont des arguments qui permettent d'inclure de telles unités lexicales dans le corpus analysé. En même temps, les expressions comme франиузская колбаса [saucisson français], франиузские овощии [légumes français] ou франиузское молоко [lait français] ont un nombre d'occurrences assez faible et leurs signifiés disposent d'un " potentiel ethnographique » assez réduit, nous semble-t-il, c'est pourquoi nous n'envisageons pas d'étudier ce type de locutions.

Comme les dictionnaires, y compris phraséologiques, ne recensent pas toujours ces expressions, nous avons utilisé les corpus de textes dénommés Corpus national de la langue russe [Национальный корпус русского языка - НКРЯ] et Frantext $^{2}$ pour vérifier la fréquence des occurrences.

Nous ne tenons pas compte des marques, labels, etc. qui constituent un groupe onomastique très nombreux qui pourrait faire l'objet d'une autre étude. Ainsi, entre 1890 et 1915, pendant la période de rapprochement des deux pays qui débouche sur l'alliance franco-russe et l'Entente cordiale, en France quelque 800 marques évoquant la Russie d'une manière ou d'une autre ont été enregistrées ${ }^{3}$. Par exemple, le vocabulaire gastronomique très sensible aux effets de mode s'est enrichi de l'entremets franco-russe et de la crème francorusse, produits de la marque Francorusse. Néanmoins, nous les citons dans certains cas pour valider les connotations propres aux appellatifs, par exemple, les chocolats Парижскій шикъ [Le chic parisien] faisant référence au phrasème correspondant.

2. Les exemples issus de ces bases de données ne sont pas spécifiés. Sauf mention spéciale, les exemples russes sont cités d'après HKPЯ, et les exemples français d'après Frantext.

3. Krauss $2007: 336-337$. 
Nous avons exploré plusieurs registres des langues nationales, y compris le langage populaire, le moins étudié mais qui s'avère précieux pour la reconstitution des stéréotypes ethniques. C'est la raison pour laquelle nous avons prêté la plus grande attention aux données émanant des parlers russes et français. Nous analysons également le langage familier, les argots et les langues littéraires ; mais nous écartons des expressions exclusivement livresques ou des termes purement techniques dont l'usage ne serait pas confirmé par des contextes relevant du langage parlé ou de la littérature de fiction.

Les données sont présentées par rubriques thématiques :

- Caractéristiques générales ; vêtements, tissus, chaussures ; cosmétiques, parfums, coiffures ; gastronomie ; objets du quotidien ; agriculture ; transports ; jeux, jouets, divertissements.

Chaque rubrique débute par la présentation des faits de la langue russe, ensuite du français. Dans certains cas, elle ne contient que les données d'une seule langue.

\section{CARACTÉRISTIQUES GÉNÉRALES}

Langue russe. La France et tout particulièrement sa capitale sont perçus comme les symboles de la civilisation, cf. Париж [Paris] « une localité ou sa partie qui a un caractère civilisé, ordonné, qui a des pratiques culturelles, des divertissements, etc. » :

Мухтуй называют здесь Парижем, потому что крестьяне (из ссыльных) ходят в пальто и танцуют кадрили

Muxtuj est nommé ici Paris, parce que les paysans (exilés) portent le manteau et dansent le quadrille. $\quad$ I. Gončarov, la Frégate Pallas $1855^{4}$.

Ainsi, par exemple, le village Kungurka (district de Revda, région de Sverdlovsk) dispose-t-il de son propre "Paris" :

Два магазина там, церква и клуб, вот и у нас Париж

Il y a deux commerces là-bas, une église et un club, c'est donc notre Paris ${ }^{5}$.

« Paris » est associé à la richesse, au luxe, aussi bien dans la mode, l'architecture que dans la gastronomie, comme le montre une sentence argotique : « Ах, Париж, Париж, Париж, как приедешь - угоришь ! » [Oh, Paris, Paris, tu y vas, et tu deviens fou!] « en parlant en plaisantant de Paris, de son luxe, de ses curiosités, etc. ${ }^{6}$ L'expression figée парижский иик (plus rarement парижская роскошь) [chic parisien, luxe parisien] a souvent donné lieu aux

4. Otin $2004: 270$.

5. ТЭ.

6. TCPC $: 27$. 
noms propres. Dans le roman de Bulgakov la Garde blanche, on cite la boutique Парижский шик ; avant la révolution de 1917, il existait une marque de chocolats Парижскій шикъ, etc. Actuellement cette appellation est utilisée pour un catalogue de mode, un type de broderie, une broche, une julienne, une composition florale de bonbons, etc. Le luxe parisien est un luxe distingué et élégant et qui n'a rien de prétentieux ${ }^{7}$. Le chic, l'éclat, le charme ne caractérisent pas que l'univers matériel de Paris et de la France, mais, par extension, les manières, le comportement, la vie intellectuelle des Parisiens, etc. ${ }^{8}$

Ces images sont à l'origine de l'appréciation positive qui se manifeste dans le sémantisme des arg. ${ }^{9}$ Париж « à propos de quelque chose de bon, d'excellent », парижский [parisien] «bon, excellent » ${ }^{10}$. La France, et en l'occurrence sa capitale, se dresse en symbole de la beauté, comme le montrent la toponymie et l'anthroponymie populaires Париж « un habitant du village Natal'ino, district de Buj, région de Kostroma » : « Красивый парень, что твой Париж » [Beau gosse, comme Paris] ${ }^{11}$, un champ dénommé Париж à proximité du village Krylatovka, district de Revda, région de Sverdlovsk, désigné ainsi parce que « Красивое поле, хорошо родит » ${ }^{12}$.

Mais aux yeux des Russes, ce chic a également son revers, son côté « blingbling », «pacotille », comme le montre le contexte cité par Dal' : « Прихотный товар, роскошный, франиузские безделушики " [Marchandise de luxe, des gadgets français $]^{13}$. C'est ce jugement qui, très probablement, explique le sens de arxang. фрянкк « pot-pourri ${ }^{14}$.

La France impose la mode dans plusieurs segments de la culture matérielle, ce qui transparaît dans l'expression парижская (франиузская) мода [mode parisienne (française)] qui peut s'accompagner d'autres qualificatifs последняя,

7. «Вот кондитерские и налево и направо - чудеса парижской роскоши и изящества » [Des pâtisseries à droite et à gauche : les merveilles du luxe français et du raffinement], E. Rastorguev, les Promenades sur la perspective Nevski, 1846; « Итак, "Паллас" ничуть не лучше ARCH-1000, но оформлена она с истинно французским изяществом - просто и элегантно », M. Konstantinovskij, « Sûr, profitable, confortable ! », la Chimie et la Vie, 1965.

8. « Он произносил их в совершенстве, с настоящим парижским шиком, и в то же время говорил “si j’aurais" вместо "si j’avais", “absolument” в смысле: ‘непременно', словом, выражался на том великорусско-французском наречии, над которым так смеются французы [...] » [Il les prononçait avec perfection, avec un vrai chic parisien, et en même temps il disait "si j'aurais" au lieu de "si j'avais", "absolument" dans le sens, «sans faute» bref il s'exprimait dans ce langage russo-français qui amuse tellement les Français], I. Turgenev, Pères et fils, 1862; « В этом увлекательном сочинении, написанном с истинно французским блеском, проходят перед нами психиатрические теории древнейших времен и вся фактическая сторона средневековых психических эпидемий », Ju. Kannabix, Histoire de la psychiatrie, 1928; «Ася же [...] всецело поддается влиянью утонченного стилиста [...] и механически нашпиговывается всевозможной французской утонченностью от символистов до мистиков. » [Assia subit l'influence du styliste raffiné [...] et ingurgite toutes sortes de raffinement français, des symbolistes aux mystiques.], A. Belyj, Entre deux révolutions, 1934.

9. Voir la liste des abréviations géographiques en fin d'article.

10. TCPC : 279 .

11. ТЭ.

12. ТЭ.

13. Dal' $3: 458$.

14. СРГК $6: 690$. 
высокая, новая [dernière, haute, nouvelle]. On doit la mode parisienne aux парижские (франиузские) франты, щееголи, модники и моднищь [dandys, petits-maîtres, élégants, élégantes], expressions qu'on peut également considérer comme des unités figées.

\section{VÊTEMENTS, TISSUS, CHAUSSURES}

Langue russe. L'importation d'articles de mode français en Russie prend de l'ampleur au XVIII siècle, cf. le phrasème одеваться по-парижски (пофраниузски) [s'habiller à la parisienne, à la française] «s'habiller avec élégance, à la mode ». C'est à cette époque que dans la garde-robe de la haute société apparaît франиузский кафтан [frac français]. L'expression est toujours utilisée dans la langue littéraire au XIX ${ }^{\mathrm{e}}$ siècle, mais le signifié est considéré comme sorti d'usage, cf. la définition donnée à франиузский кафтан par Dal' : « frac avec des basques larges et arrondies, porté dans le passé » ${ }^{15}$.

L'idée que la France impose ses goûts dans la mode vestimentaire se réfracte d'une manière particulière dans la conscience linguistique populaire. On pouvait désigner comme « français » des vêtements achetés (alt. франиузский « acheté dans le commerce », cf. « Платки купленные, французские платки в магазине » [Foulards achetés, foulards français dans le commerce ${ }^{16}$ ) ou qui ont l'air « européens » (франиузское платье [habit français] « (habit) allemand, occidental, non russe $\left.{ }^{17} »\right)$.

Les locuteurs de la langue littéraire et des patois connaissaient des foulards et des châles « français » : litt. франиузская шаль, платок [châle, foulard français] « châle carré, plié en deux, en général, à motifs " ${ }^{18}$, kostr., mord., smol. франиузский (храниузский) платок [foulard français] « foulard habillé à fleurs, le plus souvent rouge, fabriqué à partir d'un tissu acheté dans le commerce ${ }^{19}$, smol. парижский платок [foulard parisien], франиузик [petit Français] « idem ${ }^{20}$, etc. Il est à noter que dans les parlers d'Arxangelsk le foulard франиуз (храниуз) peut également être nommé а́нгельский плат [foulard d'ange] ${ }^{21}$. La dernière expression résulte de l'attraction de аглицикий плат [foulard anglais] « idem » ${ }^{22}$ et ангел [ange] « ange ». Cette contamination reflète à la fois l'idée de l'origine « étrangère » de ces foulards et celle de leur beauté «surnaturelle».

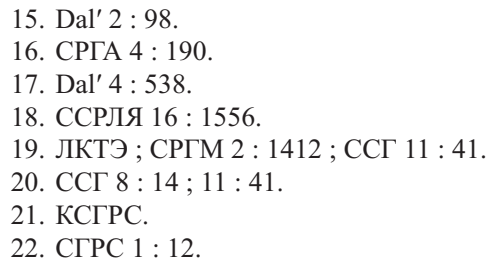


Le même constat s'impose pour les chemises, gilets et sarafans : novg. франии́зская рубаха " chemise rouge ${ }^{23}$, volog. франии́зка « gilet large brodé ${ }^{4}$ », smol. парижский сарафан « sarafan habillé, de couleur vive avec des fleurs éclatantes ${ }^{25}$. Ces pièces de vêtement n'étaient pas confectionnées en lin, tissu traditionnel des paysans russes, mais en tissus importés (coton, toile pourpre) : smol. nари́жчина " une étoffe de coton, appelée aussi "le coton rouge" 26 », mord., tul., jarosl. храниу́з, франиу́з « tissu rouge écarlate, toile pourpre ${ }^{27}$. La « francité » des tissus ne tenait pas qu'à leurs qualités (habillés, achetés) mais aussi à leur « étiologie » : ainsi, les paysans du gouvernement de Vladimir déclaraient que " porter du linge en coton est un péché, car il "avait été apporté par le Français", il faut porter celui en lin $»^{28}$.

À partir de la motivation sémantique des французские платки, сарафаны, on peut interpréter la forme intérieure moins évidente des mots пари́шки, пари́жки : arx., murm. « chaussures tricotées ou tressées en tissu, avec une fine semelle en cuir », arx. " chaussures de femmes portées en hiver, tricotées en laine, renforcées de cuir sur les pointes et les côtés ", arx. " chaussures de femmes d'hiver, "de cérémonies" $\gg "$. La dérivation du nom de la capitale française est motivée par le fait que les chaussures avec des semelles en cuir étaient considérées comme habillées. Apparemment elles étaient censées imiter les chaussures portées, selon les paysans russes, par les élégantes parisiennes : incompatibles avec les besognes paysannes, elles étaient presque décoratives.

Pour les locuteurs du russe littéraire, l'élégance parisienne est symbolisée par франиузский каблук (каблучок) [talon français] « talon haut recourbé » ${ }^{30}$, франиузский берет [béret français] « petit béret en feutre noir »:

Souvent la connaissance d'un pays se réduit à quelques stéréotypes anciens. L'un d'eux veut que les Français ne se séparent jamais de leur petit béret noir ${ }^{31}$.

Ou encore парижская (франиузская) шляпка, $\mathrm{cf.} \mathrm{:}$

[...] да они еще и не продают настоящие парижские шляпки, а выписывают себе для образца да и шьют по ним : уж где ж так сшить, как в Париже.

[...] mais ils ne vendent pas les vrais chapeaux parisiens, ils les font venir pour servir de modèle et les copient: comment peut-on faire ailleurs qu'à Paris.

A. Veltman, les Aventures puisées dans la mer de l'existence. Salomé, 1848.

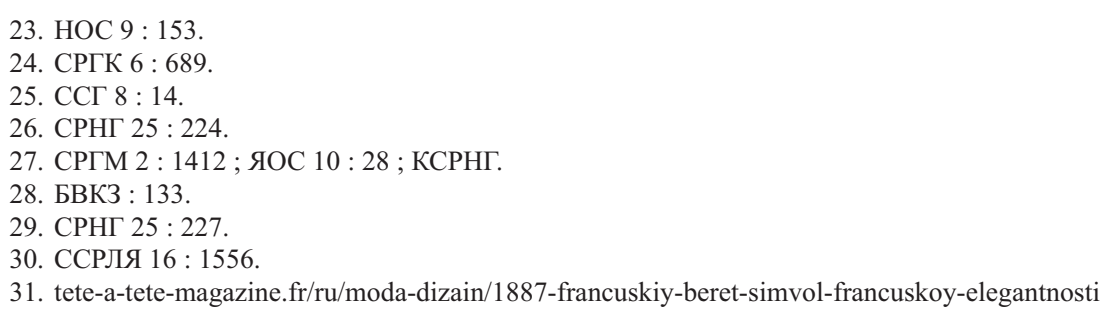


Langue française. Au XVII ${ }^{\mathrm{e}}$ siècle, les Français découvrent un maroquin qui portera le nom de cuir de Russie, parfois cuir russe, car à l'origine, importé de Russie. Sa teinte rougeâtre est évoquée dans d'autres variantes, comme cuir de roussi, vache de roussi, roussi qui relèvent de l'étymologie populaire car elles mettent en relation le terme avec le nom de la teinte roussi ${ }^{32}$. Cette matière pendant des siècles a bénéficié d'un tel prestige qu'en 1924 Chanel donne le nom de Cuir de Russie à son nouveau parfum.

Un autre produit importé tout aussi prisé était la laine de Moscovie « duvet que l'on tire de la peau des castors, sans offenser le grand poil ${ }^{33}$ utilisé pour faire des chapeaux d'excellente qualité ; il a gardé son nom malgré le fait que déjà au XVIII ${ }^{\mathrm{e}}$ siècle il était fabriqué au Canada ${ }^{34}$. Le dérivé du nom de Moscovie apparaît également dans la dénomination de l'étoffe moscovite:

Robe en moscovite gris acier, velours ciselé et soie brodée de même couleur. Mode illustrée, $1883^{35}$.

Les courtes périodes de sympathie pour la Russie ont été ponctuées par l'apparition dans les rues et les salons d'habits de style russe. Dans les descriptions de la mode cosmopolite de la Restauration, on évoque des chapeaux à la $\cos _{a q u e}{ }^{36}$, hautes toques de femmes qui évoquent la coiffe traditionnelle (nanaxa) des cosaques, et le pantalon à la russe ou (à la) cosaque, bouffant et resserré au niveau des chevilles, porté par les hommes:

J'ai mis à la mode, sans peine, / Les bolivars, les morillos, / Les nouveaux chapeaux de baleine,/J'ai porté les premiers manteaux./On me voit, sans crainte d'attaque, / Porter aussi, dès le matin, / Le pantalon à la Cosaque, / Et la cravate à la Colin.

Gabriel et Armand, les Blouses ou la soirée à la mode, $1822^{37}$.

À la fin du XIX siècle, apparaît la blouse russe munie d'un col russe mon$\operatorname{tant}^{38}$, probablement synonyme de la blouse moscovite ${ }^{39}$.

Le premier emploi de vert russe est attesté en 1814, l'année de l'entrée de l'armée russe à Paris. Ensuite, grâce aux fabricants de couleurs, le terme est

32. FEW $20: 45$.

33. DAF.

34. Morelot $1800: 194$.

35. BHVF.

36. «Les dames de l'aristocratie s'affublent de chapeaux "à la cosaque" ou de shakos à plumet qui rappellent les coiffures des uhlans. On les verra un peu plus tard porter le carrick de drap ou le spencer de velours, tandis que les hommes seront pantalonnés à la russe », Tabouis, Mousset 1951:194.

37. BHVF.

38. «On fait, cette année, des petites jaquettes sans revers qui, complètement fermées sur la poitrine, offrent l'avantage de nous épargner bien des rhumes et bien des bronchites. [...] La veste, genre blouse russe, se croise sur la gauche et semble retenue par trois gros boutons. La ceinture est faite d'une étroite bande de drap. Le tour du cou et le bas de la blouse russe sont ornés d'une bande de skungs. », Matin 1884.

39. « Grande, droite, en blouse moscovite et longue veste noire, elle penche sa pâle figure aux joues romaines, ses rudes cheveux gris coupés au-dessous de l'oreille, sur un panier où remue un petit avorton jaune, un minuscule chien en chemise de flanelle qui lève vers elle un front bossu de bonze, de beaux yeux implorants d'écureuil », Colette, la Vagabonde, 1910. 
devenu international : all. Russichgrün, angl. Russiangreen, esp. verde ruso, it. verde russo. Ce nom d'une des teintes du vert, évoquant probablement la couleur de l'uniforme de l'armée russe, dans les années 1830-1840 est utilisé essentiellement dans la description de tissus et de vêtements d'hommes ${ }^{40}$. Le terme gris russe est moins répandu.

En France, au XIX ${ }^{\mathrm{e}}$ siècle, parmi les objets caractéristiques de la mode vestimentaire russe, on évoquait les galoches, appelées dans le parler d'Anjou sabots russes et surtout les bandes de tissus enroulés autour du pied par les paysans et les soldats que les militaires français lors de la guerre de Crimée ont baptisés chaussettes russes ou de manière elliptique russes. Ensuite l'expression est passée dans la langue courante ${ }^{41}$. Les chaussettes polonaises ont à peu près la même fonction, mais elles représentent des bandes de papier ${ }^{42}$. En dépit de la xénonomination ce type de « chaussettes», tout comme les sabots russes étaient déjà portés dans la campagne française, notamment en Touraine et à Oléron ${ }^{43}$ ainsi que dans l'armée. Dans la langue populaire, les chaussettes russes peuvent également désigner sur le mode ironique l'absence de toute chaussette ${ }^{44}$.

\section{COSMÉTIQUES, PARFUMS, COIFFURES}

Langue russe. La réputation de l'industrie cosmétique et de la parfumerie française s'est répercutée inévitablement dans la langue littéraire qui contient des locutions comme франиузская косметика [cosmétiques français], франиузский парфюм [parfum français], франиузская помада [rouge à lèvres français], mais la plus connue et la plus figée est celle de франиузские духи. Dans le parler de Kostroma, on relève le détournement ironique d'un article des cosmétiques : франиузские тени [fards à paupières] « cernes sous les yeux $»^{45}$.

Dans le langage urbain actuel, on utilise des noms de coiffure tels que франиузский боб [coupe au bol française], франиузская коса [tresse française], франиузский водопад [chute d'eau française], etc.

Langue française. Pendant quelque temps à Paris, les habits « à la russe » étaient complétés par des favoris courts, appelés également les russes ${ }^{46}$.

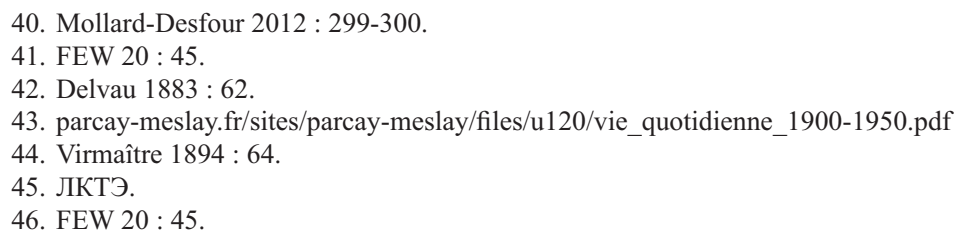




\section{GASTRONOMIE}

Langue russe. Malgré l'adage « Сытен русский стол, голоден французский $»^{47}$ [La table russe rassasie, la française laisse sur sa faim], la Russie comptait beaucoup d'admirateurs de la cuisine française, cf. :

Налейте мне ещё шампанского стакан, Я сердцем Славянин - желудком Галломан !

Versez-moi encore une coupe de champagne. Je suis slave de cœur, mais gallomane par l'estomac!

K. Batjuškov, Promenade dans Moscou, 1812.

Le prestige de la cuisine française a donné envie de l'imiter et de la reproduire à sa manière, cf. по-парижски [à la parisienne] « qualificatif typique d'un plat »:

Да, гранит виктория по-парижски ! А по-парижски-то, может, и сам повар не знает как. Переложил лист салату на другое место, вот тебе и по-парижски.

Oui, la salade victoria à la parisienne. Mais il se peut que le chef cuisinier ne sache pas comment ça se fait à la parisienne. Il déplace une feuille de salade, et la voilà « à la parisienne »!

I. Šmelev, Garçon de restaurant, $1911^{48}$.

Le plus souvent le qualificatif « français » se rapporte dans les différents registres de la langue russe au pain et à la pâtisserie : litt. франиузская булка (франиузский хлеб) [baguette, pain français] désigne un pain de froment long aux extrémités arrondies qui s'oppose au pain de seigle plus populaire chez les Russes. Dans les parlers du sud, ce pain a des appellations particulières : novoros., odes. франзо́ля, франсо́ля, франщо́ля, don. франзу́лька, хрансо́ль ${ }^{49}$. Par métonymie, ces termes peuvent désigner des pâtisseries spéciales : krasnodar. франзо́ля, sans loc. франзу́лька, don., kuban., odes. франзо́ль " pâtisseries en forme de 8, bretzel », odes. хранзо́ль, хранзо́ля « brioche » ${ }^{50}$.

$\mathrm{Au} \mathrm{XIX}^{\mathrm{e}}$ siècle, on fabriquait un gâteau nommé франиузский ветер [vent français] « crème, crème fouettée, parfois avec des œufs $»^{51}$. Aujourd'hui, ce gâteau porte dans le milieu urbain le nom de франиузский поиелуй [baiser français] : à base de crème chantilly, il a une forme pyramidale " ondulée ${ }^{52}$. Très probablement l'image du « baiser» a été empruntée à la meringue, préparation à base de blanc d'œuf et de sucre, désigné en russe par le gallicisme безе ${ }^{53}$. L'appellation ethnonymique s'est imposée non seulement pour désigner l' " origine »

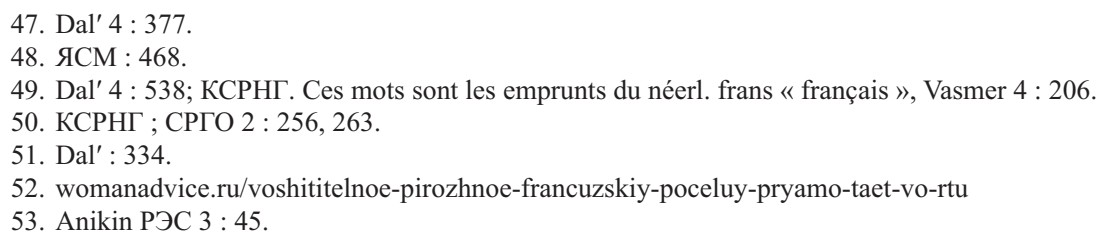


de la douceur mais aussi en raison du figement франиузский поиелуй dans son acception première « baiser amoureux, profond, avec la langue » qu'on appelait en français le baiser florentin. Il est tout à fait logique que, par ailleurs, on donne aux meringues le nom de испанский ветер [vent espagnol] ${ }^{54}$, cf. all. Spanischer Wind « item ».

Parmi les condiments, франиузская горчица [moutarde française] à base de graines de moutarde noire (Brassica nigra) cultivée entre autres en France mais pas en Russie, rencontre un vif succès. Elle servait également à la préparation de la vinaigrette - французская заправка [assaisonnement français].

Tout aussi connus sont франиузские сыры [fromages français]. On considérait comme un produit de luxe les plats à base de truffes - франиузские трюфели [truffes françaises]:

С французским лучшим трюфелем тарелки я лизал, напитки иностранные из рюмок допивал...

Je sauçais les assiettes des meilleures truffes françaises, je finissais les verres des meilleures boissons étrangères...

N. Nekrasov, Qui vit bien en Russie ?, 1864.

Les célèbres alcools français ont connu un destin particulier en Russie. Ainsi, le cognac, au début exotique pour les Russes, a été désigné par le biais de la vodka, boisson plus répandue, litt. vieil. французская водка [vodka française] « vodka résultant de la distillation des vins de raisin, cognac $»^{55}$. Actuellement l'expression est inusitée et remplacée par франиузский коньяк [cognac français]. Les locutions французское вино [vin français] et франиузское шампанское [champagne français] représentent aussi des figements.

Si tous les produits évoqués jusque-là avaient une « vraie » origine française, la question de франиузское масло [beurre français] est plus complexe. On appelait ainsi le beurre mélangé au lard, comme le montre cet extrait d'un livre de cuisine :

Сало составляет самую обыкновенную и общеупотребительную торговую примесь в коровьем масле; так называемое французское масло в хороших ресторанах (80 коп. за фунт) почти все состоит из сала, перемешанного более тщательно и искусно.

Le lard représente la composante la plus courante et commune du beurre de vache, le soi-disant beurre français des bons restaurants ( 80 kopecks la livre) se compose presque entièrement de lard mixé plus habilement et soigneusement ${ }^{56}$. 
Il n'est pas impossible qu'on y ait vu une habile escroquerie:

На французском масле, Сделанном из сала, Испекла природа Этого нахала.

La nature fabriqua cet effronté avec du beurre français fait de lard.

N. Nekrasov, les Contemporains, 1875.

Mais on ne peut pas exclure le lien avec un autre produit. Le beurre mélangé au lard pouvait être rapproché par les consommateurs avec la margarine. Apparue en France en 1869, elle contenait de la graisse de bœuf et coûtait moins cher que le beurre. Dans ce groupe lexical, il faut également évoquer volog. храниузики [Français] « lard brûlé » ${ }^{57}$. On peut supposer que le terme fait écho à la guerre napoléonienne : le lard poêlé est le résultat d'une action assimilée à une opération militaire visant la destruction de l'ennemi, tout comme le battage, comme nous le verrons dans la rubrique « Agriculture».

Langue française. La principale contribution de la Russie à la gastronomie française reste le service à la russe, qui est entré dans les mœurs dans la deuxième moitié du XIX siècle. D'après une légende, les Français l'ont découvert chez Alexandre Kurakin, ambassadeur de Russie en France entre 1808 et $1812^{58}$. À la différence du service à la française, le service à la russe exige qu'on serve les plats l'un après l'autre.

Parmi les plats « russes » adaptés par la cuisine française, le plus connu est la salade (à la) russe, nommée au XIX ${ }^{\mathrm{e}}$ siècle également salade de légumes à la russe $^{59}$. D'autres langues ont emprunté le nom par le biais du français. Partout le terme désigne une salade de légumes crus ou cuits, assaisonnée de mayonnaise. La popularité du plat se confirme par l'usage métonymique de l'expression qui signifie un mélange d'éléments disparates :

Je suis né en Autriche-Hongrie ; c'est devenu la Roumanie, c'était russe après, c'était allemand après, c'est redevenu roumain après, et c'est redevenu russe, et maintenant c'est ukrainien! Alors je suis né où ? Je suis né nulle part. Une vraie salade russe ! K. Bernfeld, les Portes de l'espérance, 2003.

Il existe un autre nom « slave » donné à cette préparation : macédoine à la moscovite. Dans les livres de cuisine, on rencontre la salade moscovite composée également de légumes (betteraves, tomates, haricots verts), d'œufs et, bien sûr, assaisonnée de mayonnaise.

Nous avions déjà eu l'occasion de montrer que le caractère gras est envisagé par les étrangers comme l'un des traits distinctifs de plats « russes $»^{60}$. Ainsi parmi d'autres plats « à la russe » on notera des plats noyés dans la mayonnaise comme salade de truffes à la russe où les truffes sont recouvertes d'une couche

57. КСГРС.

58. À propos des réactions au service à la russe, voir : Kabakova 2013 : 35-36.

59. TLFi.

60. Voir l'analyse dans : Berezovič 2014 : 148-153. 
de mayonnaise et de moutarde anglaise ${ }^{61}$ ou encore poisson (ou crustacés) à la russe, telle la côtelette de saumon à la russe : le saumon est servi avec sa sauce à la mayonnaise et au caviar avec des morceaux de homard ou de langouste ${ }^{62}$ ou encore ceufs à la russe : moitié de blanc d'œuf cuit farcie d'un mélange de jaune, de caviar ou, à défaut, de thon émincé, d'anchois ou de jambon, toujours servie avec de la mayonnaise ou de la crème fraîche ${ }^{63}$. Les deux dernières recettes laissent penser qu'outre la mayonnaise, le caviar est également envisagé comme un élément fondamentalement « russe ».

Parmi les plats « russes » à la mayonnaise connus hors la France nous évoquerons le gâteau russe, servi partout au Québec à l'occasion des fêtes : les recettes sont nombreuses, mais c'est toujours une sorte de pain surprise, où une couche de salade au poulet se superpose à la salade d'œufs, assaisonnée généreusement de mayonnaise ou de mélange de mayonnaise et de crème fraîche.

Le plus grand nombre d'appellations « russes » sont constatées dans la pâtisserie. Souvent il s'agit de créations d'un pâtissier ou d'un cuisinier de renom. La pâtisserie comme la mode réagit facilement à l'actualité politique. Par exemple, la charlotte (à la) russe inventée par le célèbre Antonin Carême, porte son nom de manière injuste, selon ses propres mots :

Quelques personnes nomment cette charlotte à la russe, tandis que je l'ai dénommée à la parisienne, attendu que j'en eus l'idée pendant mon établissement ; car les premières qui aient paru, ce fut chez les ministres de la Police et des Relations extérieures où je les ai envoyées toutes moulées au moment du service, avec les commandes de pâtisserie qui m'étaient faites pour ces grandes maisons ${ }^{64}$.

En 1892, l'alliance franco-russe est signée. La sympathie pour la Russie est à son apogée, et les pâtisseries et les restaurants regorgent de nouveautés « russes ». Ces inventions sont essentiellement régionales. Vers 1900, à Angers le gâteau Franco-Russe détrône les autres spécialités locales ${ }^{65}$. On suppose que l'alliance est également à l'origine de l'appellation lyonnaise pain russe « petit pain aux raisins », sans que les sources ne soient citées. Parmi d'autres pâtisseries évoquant la Russie, citons entremets russe « pain perdu » et les tartelettes à la russe, garnies de marmelade d'abricots ${ }^{66}$.

Plus connu est le gâteau russe - ou juste le russe, lancé en 1925 par la pâtisserie Artigarrrède à Oloron-Sainte-Marie et ensuite imité dans toute l'Aquitaine. C'est un gâteau composé de trois couches de biscuits, intercalées de pralinés d'amandes et de noisettes. L'origine du nom reste obscure mais on pense qu'il est dû soit aux amandes de Crimée, soit à la couleur blanche du gâteau qui doit

61. Dumas $2000: 550$

62. TLFi.

63. j.poitou.free.fr/pro/html/voc/russe.html

64. Carême $1815: 446$.

65. Verrier, Onillon $1908: 212$.

66. Perrier-Robert 2012. 
évoquer les plaines enneigées de Russie. Les deux hypothèses semblent peu probables.

Pour d'autres noms, on peut supposer que la « russité » affichée dans les noms correspond à l'abondance de la crème qui entre dans la composition et qui s'inspire du stéréotype « gras » de la nourriture russe. C'est le cas de la tartine russe, connue dans le nord de la France et en Belgique, appelée galette russe, à Tourcoing ; il s'agit d'une sorte de sandwich composé de deux biscuits croquants à base de cassonade généreusement fourrés de crème au beurre et au sucre ${ }^{67}$.

Le thé (au goût) russe occupe une place particulière en France et en Europe en général. On peut expliquer l'expansion de cette appellation par la réputation du thé comme boisson nationale en Russie. En général, il s'agit du thé aux agrumes. Plusieurs raisons sont évoquées quant à l'origine du nom et de la recette. L'une évoque l'amour de la famille impériale russe pour ce type de mélange, l'autre cite l'habitude des Russes de boire le thé avec une rondelle de citron ou d'orange qu'ils ont importée en France. C'est notamment le cas de la maison Dammann qui attribue l'origine de leurs recettes « russes » à la manière dont consommait le thé l'épouse russe du fondateur de la société ${ }^{68}$. Cette « russité » se décline par les marques de thé sous divers noms « russes » ${ }^{69}$.

La trace laissée par le Cosaque dans ce groupe lexical est plus modeste. Dans le Lyonnais, on fabriquait des bonbons entourés d'un papier doré ou argenté avec un madrigal (par la suite une histoire drôle) et un pétard. C'est cette dernière surprise qui explique probablement les noms attribués en 1814 à ces papillotes : cosaques, à la cosaque, papillotes cosaques, bonbons cosaques ${ }^{70}$.

Évoquons aussi le cocktail cosaque, mélange de bière, Picon et de sirop de grenadine ou bien de vodka, bitter sans alcool, liqueur de fraises des bois ${ }^{71}$. Il est clair que dans la deuxième version le nom « russe » s'explique par l'usage de la vodka, russe par excellence, tandis que la motivation de la première recette est moins évidente.

\section{OBJETS DU QUOTIDIEN}

Langue russe. Parmi les menus objets du quotidien citons франиузская булавка [épingle française] « épingle de sûreté, dite de nourrice » ${ }^{72}$ dont le nom plus courant est английская булавка [épingle anglaise], ce qui souligne sa perception en tant qu'objet « européen ». Un autre objet commun a également la même double appellation : франиузский замок [serrure française], appelé

67. pignonfixe.com/showthread.php?tid $=10999 \&$ page $=2372$

68. fr.wikipedia.org/wiki/Dammann Fr\%C3\%A8res

69. Voici un exemple de la maison Petrossian qui fait appel également à l'histoire familiale : « Le thé Tante Irina et le thé Tante Bella sont les descendants des recettes de ces deux tantes, dont l'une parfumait son thé de fruits rouges tandis que l'autre préférait les agrumes. » (petrossian.fr/fr/aux-origines-du-the-russe).

70. Alard $1814: 155$.

71. Perret $2002: 395$.

72. ССРЛЯ $16: 1556$. 
aussi английский замок [serrure anglaise] « serrure capable de bloquer l'ouverture sans l'introduction de la clef correspondante » (connue en français sous le nom de serrure américaine). Le caractère « étranger » de la serrure apparaît également dans la variante utilisée dans le jargon des criminels франиyз [Français] ${ }^{73}$. La serrure « française » s'ouvrait avec французский ключ [clef française] ${ }^{74}$. Франиузский ключ est également un terme désignant un instrument qui sert à serrer et desserrer des écrous etc. Les Anglais utilisent aussi, entre autres, le terme french-wrench ${ }^{75}$, tandis qu'en français on préfère l'appeler clef anglaise, ou en italien chiave inglese ${ }^{76}$.

Dans les articles du quotidien on trouve aussi litt. франиузский табак [tabac français] « sorte du tabac à priser ${ }^{77}$.

Parmi les produits chimiques connus du grand public, citons парижская (франиузская) зелень [vert parisien, français], un insecticide, mais aussi un pigment de couleur verte. On rencontre d'autres noms dérivés du toponyme dans le lexique des couleurs pour la simple raison que la France a toujours exercé son autorité dans le domaine coloristique, cf. (франиузская) лазурь (синь) [azur (bleu) (français)] « nuance proche de bleu de Berlin (de Prusse) $\gg^{78}$.

La langue russe utilise aussi les termes франиузская кровать [lit français] qui désignent en général un lit king-size, et французские окна [fenêtres françaises] qui ne sont pas les « fenêtres à la française » pratiquées en France mais plutôt des portes-fenêtres, qui, selon la publicité, rehaussent le prestige de leur propriétaire.

Langue française. La France a fait connaissance avec les cigarettes russes lors de la guerre de Crimée. Aujourd'hui, ce terme est connu grâce à une marque de produits : en 1945, le biscuitier Delacre lance un nouveau biscuit qu'il baptise cigarettes russes à cause de sa forme roulée.

Par analogie avec la structure des poupées russes (voir infra), on désigne casserole russe ou russe n.f., une casserole ronde à bord vertical munie d'une queue qui peut s'emboîter dans une autre casserole, car ces casseroles sont vendues en batterie ${ }^{79}$.

Plus rare est quimp. russe n.m. «vase de nuit ». Dans cette xénonomination on peut deviner la connotation historique péjorative, confirmée par le contexte cité dans le dictionnaire du parler "s'asseoir sur le russe " ${ }^{80}$. L'argotique cosaque " poêle à chauffer » doit probablement son nom à sa forme qui rappelle la toque des cosaques ${ }^{81}$.

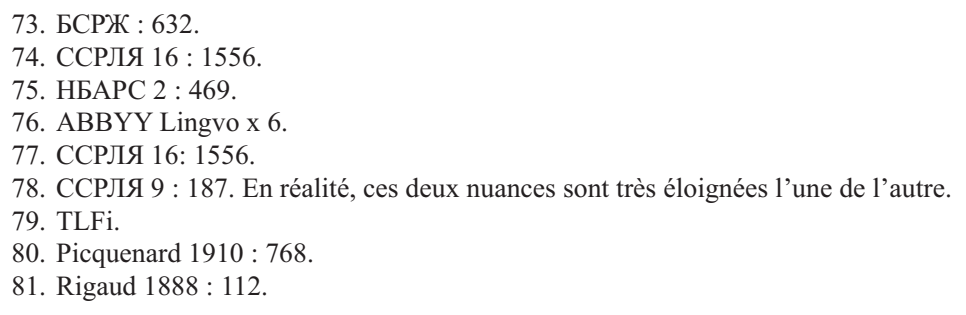




\section{AGRICULTURE}

Langue russe. Nous supposons que le souvenir de la guerre napoléonienne transparaît, de manière indirecte, dans volog. франиузы « balle, résidu du battage impropre à la consommation ${ }^{82}$. Le battage, opération de destruction, est associé à la bataille contre l'ennemi (voir supra храниузики « lardons brûlés »). Cette hypothèse est étayée par la devinette « Маленький Кузя побил всех французов » [Petit Kuzja battit tous les Français] (réponse : le battoir) ${ }^{83}$.

Langue française. La présence « russe » est attestée dans un champ lexical aussi conservateur que l'agriculture. En Mayenne et en Normandie, cosaque est une meulette composée de deux à trois (Bas-Maine) ou quatre à cinq gerbes de blé qu'on recouvre avec une autre, l'épi en bas (pays de Caux) ou neuf gerbes recouvertes avec la dixième (Le Havre). En outre, à Saint-Aubin-Fosse-Louvain (Mayenne), on relève le verbe correspondant kozaké « mettre le grain en cosaque $»^{84}$. Lazar Saineanu doutant du lien entre les Cosaques et cosaque " moyette ", proposa une autre étymologie : cosaque « le nom enfantin donné à l'oie ", attesté en Bas-Maine et en Haute-Bretagne ${ }^{85}$. Pourtant elle nécessite d'autres arguments, tandis que l'étymologie « militaire » est confirmée par un fait analogue : en Picardie, une meulette de blé composée de dix-sept gerbes disposées en forme de croix et la dernière, nommée bonnet, placée au sommet, est appelée cavailler. Et le dictionnaire évoque l'origine probable de l'objet et de son nom :

La confection est due, paraît-il, aux Cosaques venus en France en 1815, ressemblant de loin à des cavaliers ${ }^{86}$.

Le journaliste Georges Dubosc qui décrit la coutume du pays de Caux avance à peu près la même version :

Ce mode serait venu de prisonniers ou de soldats autrichiens ou russes qui, sous l'Empire, auraient introduit dans nos pays normands cette façon de disposer les gerbes ${ }^{87}$.

Mais, compte tenu des parallèles attestés dans d'autres langues ${ }^{88}$, la motivation est un peu différente : il s'agit probablement de la référence aux conflits militaires et la figure anthropomorphe de la meulette évoque l'adversaire.

82. КСГРС

83. ЭМТЭ. Ces dénominations ont des parallèles : volog. патаров оставить [laisser des Tatars] « dans un champ, laisser une zone non fauchée ("bourdon") à la suite d'un écart involontaire », ukr. щвед « couenne frite », voir l'analyse détaillée dans Berezovič 2014 : 217-219.

84. Dottin 1899 : 300 ; FEW $20: 39$; Dubosc 1898.

85. Saineanu $1925 / 1: 153-154$.

86. Ledieu $1893: 41$.

87. Dubosc 1898 .

88. Par exemple, slov. dial. moskál’ « gerbe supérieure de la meulette laissée dans un champ », SSN 2: 191. 


\section{TRANSPORT}

Langue russe. La rubrique ne contient qu'un seul exemple mais important : volog. парижа́ны [Parisiens] " traîneau décoré, "de cérémonie" " ${ }^{89}$. On doute fort de son origine française et de sa ressemblance avec un modèle parisien. Il s'agit plutôt des sèmes « beau, décoré » qui participent de la représentation de Paris dans l'imaginaire populaire russe.

\section{LOISIRS : JEUX, JOUETS, DIVERTISSEMENTS}

Langue française. La langue littéraire s'est enrichie de nombreux noms de phénomènes qui soit sont arrivés de Russie, soit ont été définis comme « russes » (ou « cosaques ») en raison du contexte général. Parmi les objets emblématiques de la Russie, figure en premier lieu la poupée russe - en réalité, originaire du Japon - dont le concept d'objets emboîtés a été étendu à d'autres objets, voir supra la casserole russe.

Parmi les divertissements, il faut indiquer l'une des variantes du billard, nommée le billard russe ou la pyramide russe qui, en effet, a été élaboré(e) en Russie tout au long du XIX ${ }^{\mathrm{e}}$ siècle.

À la différence du billard, la roulette russe est une création attribuée aux Russes par un écrivain américain, Georges Surdez, qui publie en 1937 une nouvelle éponyme où il décrit les règles du jeu. Depuis, sa Russian roulette est entrée dans toutes les langues y compris en russe ${ }^{90}$. Sa popularité mondiale se traduit par l'usage métonymique de l'expression, de loin plus fréquent que l'usage direct:

Sex Pistols ! Un jour, enfin, ce rock-là reprendrait sa place et la musique redeviendrait un jeu. Une zone haute tension. Faire du rock redeviendrait une roulette russe.

Bayon.

Tout aussi populaire est le terme montagnes russes. Cette attraction, qui a connu une diffusion internationale large mais pas toujours sous ce nom, a été construite pour la première fois à Belleville à Paris en 1816 (ou d'après d'autres sources, en 1817). Elle devait probablement rappeler les collines enneigées de Russie, que les Russes descendent en luges. Mais le choix du nom tient aussi, et surtout, au contexte d'une certaine « russomanie » qui s'installe en France à cette période. L'expression est largement utilisée au sens figuré « descentes et montées successives », par exemple dans l'argot d'aviateurs : (faire les) montagnes russes « tanguer en avion », « ne pas voler parallèlement au sol mais en montant et en descendant $\gg{ }^{91}$. Le terme convient à la description des mauvaises

89. КСГРС

90. Zelenin 2004.

91. Esnault 1919: 356 
routes (même si on ne peut pas affirmer que cette image des routes russes est ancrée dans la conscience des locuteurs français) :

Le terrain est dur, coupé de ravins. Je le connais bien : c'est une vraie "montagne russe" sans horizon, qui épuise, décourage et semble doubler les distances.

J. Malaurie, les Derniers Rois de Thulé avec les Esquimaux polaires face à leur destin, 1955.

L'image de grands écarts s'applique aussi à la description des états psychiques instables :

Les vieux ressorts de Sardou fonctionnent à coup sûr. $\mathrm{M}^{\text {lle }}$ Arletty, après les montagnes russes du rire et des larmes, n'a aucune peine à devenir épique.

J. Cocteau, le Foyer des artistes, $1947^{92}$.

\section{QUELQUES REMARQUES FINALES}

La comparaison des univers d'objets quotidiens nommés par la langue russe et la langue française fait apparaître la présence massive d'objets « français » en Russie, dans toutes les couches sociales, de la paysannerie à la noblesse pour qui le français était souvent la langue maternelle. En revanche, les artefacts « russes » en français portent un caractère épisodique. Dans ce sens, l'association de la France et du « français » à la mode, au luxe, à l'éclat, même si on les accuse parfois de superficialité, est très pertinente. De l'autre côté, la Russie et le monde matériel « russe » n'ont pas d'image bien précise dans le contexte français.

Dans les deux langues, les champs lexicaux les plus élaborés sont ceux de l'alimentation et de l'habillement. Mais leur nature est différente dans les deux traditions : les notions de mode et de cuisine française sont profondément ancrées dans la civilisation russe depuis le XVIII ${ }^{\mathrm{e}}$ siècle et, au fond, ne dépendent que très peu de la conjoncture politique, tandis que les habits et les plats « à la russe » obéissent à des modes assez volatiles qui correspondent aux périodes relativement courtes de rapprochement des deux pays.

Hubert Bergmann dans son analyse des significations secondaires des mots Russe, russe, Russie en allemand propose de regrouper les signifiés en trois catégories : la première réunit des objets qu'on connaissait réellement, la deuxième, des objets fictifs, et la troisième où la nature de l'objet est incertaine ${ }^{93}$. En ce qui concerne la connaissance réelle des objets « étrangers », la situation en France et en Russie était différente. Les objets « français »- habits, plats, pâtisseries - étaient à l'origine importés de France ou fabriqués sur place par des artisans français qui pendant des décennies ont œuvré en Russie. En revanche, les objets « russes », à quelques rares exceptions, comme le cuir de

92. TLFi.

93. Bergmann $2012: 50$. 
Russie ou la laine de Moscovie, réellement importés de Russie, ont été observés à l'occasion d'une connaissance brève lors des conflits militaires.

Il faut également préciser que la démarcation entre les catégories proposées par Bergmann reste floue et les dénominations fictives peuvent relever d'observations directes. Certains plats reconnus comme « russes » fournissent des exemples instructifs de cette « construction » de la « russité » : il s'agit de plats gras (à base de beurre, de crème, de mayonnaise) ou de plats avec des ingrédients réputés « russes » comme le caviar. La « russité » de ces derniers peut être complètement imaginaire, comme dans le cas des agrumes des thés parfumés.

Dans plusieurs termes russes analysés, le qualificatif « français » signifie avant tout « étranger, européen, occidental », d'où les dénominations synonymiques avec le qualificatif " anglais ». Souvent il contient un sème supplémentaire d'appréciation positive : « à la mode », « cher », « acheté », " prestigieux », " joli », " habillé », etc. En français, le fait de la nomination « étrangère » dans la mode ou la gastronomie est un signe, d'une part, d'amour pour l'exotisme et, d'autre part, de respect pour la tradition en question. Le sème " mauvais » est très peu présent dans ce domaine (французское масло, chaussettes russes).

Il faut constater que l'omniprésence d'objets « français » dans la vie quotidienne des Russes est rééquilibrée par les distractions « russes », soit importées de la Russie (poupée russe, billard russe), soit désignées comme « russes » en écho à la « russomanie » ambiante (montagnes russes), soit attribuées aux mœurs russes (roulette russe). Pourtant, on peut relever dans les deux derniers termes une certaine logique : les deux font appel à l'extrême et dans les stéréotypes véhiculés depuis des siècles, le Russe est tiraillé entre des passions extrêmes.

Les images respectives du « russe » et du « français » sont assez riches. Leur formation relativement tardive et la connaissance personnelle des Russes et des Français font que les images sont traitées de manière concrète, sur le mode ethnographique et contiennent peu de xénonomination avec les caractéristiques « faux », « anormal », etc. En russe, dans ce type de xénonomination, on rencontre beaucoup plus fréquemment les ethnonymes « tzigane », « juif », « allemand », « tatar ».

En même temps, la composante subjective est perceptible : ainsi dans l'expression франиузское масло « beurre mélangé au lard» on peut deviner le motif du trafic qui fait partie de l'image stéréotypée du Français en russe ; dans le nom de la pâtisserie à base de crème chantilly франиузский поцелуй on reconnaît la thématique de la sensualité attribuée aux Français. L'expression tartine russe désignant une pâtisserie composée de deux biscuits intercalés d'une épaisse couche de crème à base de beurre se nourrit du stéréotype ancrée dans la conscience langagière des Français de l'opulence, de l'excès propres aux Russes, idée qui coexiste paradoxalement avec l'idée du quotidien primitif et ascétique des Russes, cf. chaussettes russes « absence de chaussettes ». Ces caractéristiques 
ne sont pas qu'une simple projection de traits de caractères et de spécificités du comportement des Russes et des Français sur le registre des objets. Elles les complètent en faisant la lumière sur des aspects du stéréotype moins évidents mais d'autant plus précieux. Dans la reconstitution des stéréotypes langagiers, les rapports systémiques des connotations sont révélateurs. Ainsi, en russe, « français » apparaît comme synonyme d' " européen » en général (« anglais », « allemand », « espagnol ») : франиузское платье = немецкое платье, франиузская булавка = английская булавка, франиузский ветер = испанский ветер. En français, russe peut se rapprocher de cosaque et évoquer un certain Orient. Cette tendance d'associer la Russie à l'Orient - ou au Nord - se confirme dans d'autres domaines lexicaux, et notamment la nature. Dans la nomination, polonais peut sporadiquement apparaître comme équivalent de russe (chaussettes russes chaussettes polonaises).

L'appréciation de ces images est assez complexe; il est difficile de la définir de manière univoque et elle obéit à un certain nombre de facteurs :

- le contexte historique : les nominations qui reflètent les événements de la guerre napoléonienne ont inévitablement un caractère négatif, tandis que les expressions nées en 1815 et pendant l'alliance franco-russe ont des connotations positives ;

- l'idiome où le lexique étudié est utilisé : la noblesse, les élites russes étaient francophones, donc l'utilisation méliorative du lexique et de la phraséologie mentionnant le « français » caractérise plutôt la langue littéraire russe que les parlers.

De manière générale, la « francité » a une image plus positive en russe que la « russité » en français. Une place toute particulière dans l'imaginaire des Russes est réservée à Paris, symbole de la beauté, de la splendeur, et donc objet de grandes attentes.

La perspective de notre étude ethnolinguistique consiste à recréer l'image la plus exhaustive des reflets langagiers mutuels russo-français en tenant compte des données obtenues lors de l'analyse d'autres domaines de la réalisation des stéréotypes : le lexique « comportemental », « caractériel » ainsi que celui de la sphère spirituelle, des phénomènes climatiques et de la toponymie des deux pays. 


\section{ABRÉVIATIONS}

all. - allemand

alt. - d'Altaj

angl. - anglais

arg. - argotique

arxang - d'Arxangelsk

don. - de la vallée du Don

esp. - espagnol

it. - italien

jarosl. - de Jaroslavl

kostr. - de Kostroma

krasnodar. - de Krasnodarsk

kuban. - de Kuban'

litt. - littéraire

$$
\begin{aligned}
& \text { mord. - de Mordovie } \\
& \text { murm. - de Murmansk } \\
& \text { néerl. - néerlandais } \\
& \text { novg - de Novgorod } \\
& \text { novoros. - de Novorosijsk } \\
& \text { odes. - d'Odessa } \\
& \text { quimp. - quimpérois } \\
& \text { slov. - slovaque } \\
& \text { smol. - de Smolensk } \\
& \text { tul. - de Tula } \\
& \text { ukr. - ukrainien } \\
& \text { vieil. - vieilli } \\
& \text { volog. - de Vologda }
\end{aligned}
$$

\section{OUVRAGES CITÉS}

БСРЖ - V. M. МOKIENKO, T. G. NikitinA (eds.), Большой словарь русского жаргона, SPb., Norint, 2000.

БВКЗ - Быт великорусских крестьян-землепашцев. Описание материалов этнографического бюро князя В. Н. Тенишева. (На примере Владимирской губернии), В. M. Firsov, I. G. Kiseleva (eds.), SPb., Evropejskogo Doma, 1993.

КСГРС - Fichier du Dictionnaire des parlers du Nord russe de l'Université de l'Oural, département de russe et de linguistique générale, Ekaterinburg.

КСРНГ - Fichier du Dictionnaire des parlers populaires russes, Institut d'études linguistiques, Académie des science de Russie, $\mathrm{SPb}$.

ЛКТЭ - Fichier lexicographique de l'Expédition toponymique de l'Université de l'Oural (département de russe et de linguistique générale), Ekaterinburg.

НБАРС - Новый большой англо-русский словарь, Moskva, 2002, vol.1-3.

НКРЯ - Наџиональнылй корпус русского языка, ruscorpora.ru/

НОС - Новгородский областной словарь, Novgorod, 1992-1995, vol.1-12.

СГРС - Словарь говоров Русского Севера, А. K. MATVEeV (éd.), Ekaterinburg, 2001, vol. 1.

CРГА - Словарь русских говоров Алтая, I. A. VoroB'EVA, A. I. IvANovA (eds.), Barnaul, 1993-1998, vol. 1-4.

СРГК - Словарь русских говоров Карелии и сопредельных областей, sous la dir. de A. S. GERD, SPb., LGU, 1994-2005, vol. 1-6.

СРГМ - Словарь русских говоров на территории Республики Мордовия, SРb., Nauka, 2013, vol. 1-2.

СРГО - Словарь русских говоров Одесщчины, Odessa, AstroPrint, 2000, vol. 1-2.

СРНГ - Словарь русских народных говоров, Moskva - Leningrad, 1965, vol. 1.

ССГ - Словарь смоленских говоров, L. Z. BojarinOva, A. I. IVANOvA (eds.), Smolensk, Smolenskij gosudarstvennyj pedagogičeskij universitet, 1974-2005, vol.1-11. 
ССРЛЯ - Словарь современного русского литературного языка, Moskva - Leningrad, 1948-1965, vol. 1-17.

Cтереотипы в языке, коммуникации и культуре, L. L. Fedorov (éd.), Moskva, RGGU, 2009.

TCPC - Толковый словарь русского сленга, V. S. Elistratov, Moskva, AST-Press, 2007.

TЭ - Fichiers onomastiques de l'Expédition toponymique de l'Université de l'Oural, département de russe et de linguistique générale, Ekaterinburg.

ЭМТЭ - Fichiers de documents folkloriques et ethnographiques de l'Expédition toponymique de l'Université de l'Oural, département de russe et de linguistique générale, Ekaterinburg.

ЯОС - Ярославский областной словарь, sous la dir. de G. G. Mel'ničenko, Jaroslavl, 1981-1991, vol. 1-10.

ЯСМ - Язык старой Москвы : лингвоэнщиклопедический словарь, ELISTRATOV V. S. Moskva, Astrel', 2004, $2^{\mathrm{e}}$ éd.

ABBYY - Lingvo х 6: двадиать языков, lingvo.ru

BHVF - Base Historique du Vocabulaire Français, cnrtl.fr.

DAF - Dictionnaire de l'Académie française, 4éd., Paris, 1762.

FEW - Französisches Etymologisches Wörterbuch, WARTBURG W. von., Leipzig Bonn - Basel, 1928-2002, 25 vol.

SSN - Slovník slovenských nářečí, Bratislava, 1994, [T.] 1.

TLFi - Le Trésor de la Langue Française informatisé, cnrtl.fr

Stereotypy $w$ języku $i$ w kulturze, sous la dir. de S. NiEBrZEGOWSKA-BARTMIŃSKA, S. Wasiuta. Lublin, Polihymnia, 2009.

\section{BIBLIOGRAPHIE}

Avdeeva E. A., Maslov N. N. 1912. Поваренная книга русской опытной хозяйки, $\mathrm{SPb}$.

Anikin A. E. 2007. Русский этимологический словарь, Moskva, Rukopisnye pamjatniki drevnej russi, vol. 1.

BARTMINSKIJ E. 2005. « Стереотип как предмет лингвистики », in : ID., Языловой образ мира : очерки по этнолингистике, Moskva, Indrik, p. 133-158.

BEREZOVIČ E. L. 2014. Русская лексика на общеславянском фоне: семантикомотивационная реконструкция, Moskva, Russkij Fond Sodejstvija Obrazovaniju i Nauke.

DAL' V. I., Толковый словарь живого великорусского языка, SPb. - Moskva, 18801882 [1989] t. 1-4, 2 éd.

Отіл Е. С. 2004. Словарь коннотативных собственных имен, Doneck, Jugo-Vostok.

PlungJan V., RaxiLINA E. 1996. «"С чисто русской аккуратностью” : к вопросу об отражении некоторых стереотипов в языке », Московский лингвистический журнал, t. 2, p. 340-351. 
ROMAŠKo S. A. 2009. « Стереотип: к языковой и культурной археологии слова и понятия », Стереотипь в языке, коммуникации и культуре, Moskva, RGGU, p. $215-227$.

VASMER M. 1964-1973. Этимологический словарь русского языка, Moskva, t. 1-4.

Zelenin A. V. 2004. « Русская рулетка: вчера и сегодня », Русская речь, nº 1, p. $112-118$.

ŽDANOVA V. 2005. «Поляк глазами немцев: актуальный языковой и социокультурный стереотип », Etnolingwistyka, nº 17, p. 197-212.

ŽERNOVAJA O. R. 2010. «Этнокультурные стереотипы как отражение меняющейся культурной и политической реальности общества», Политическая лингвистика, $\mathrm{n}^{\circ} 2$, p. 109-113.

Alard M.-J.-L. 1814. Dictionnaire des sciences médicales, vol. 9, Paris,

Amossy R., Herschberg Pierrot A. 2011. Stéréotypes et clichés, Paris, A. Colin, $3^{\mathrm{e}}$ éd.

BERGMANN H. 2012. « Zu deutsch Russe, russisch, Russland und seinen sekundären Bedeutungen », in : Anreiter P., KienPointner M., Ivo Hajnal (Hsg.), In simplicitate complexitas : Festgabe für Barbara Stefan zum 70. Geburtstag, Wien, Praesens-Verlag, p. 49-68.

BlanchaRd R., CHABOt J., KaSPARIAN S. 2011. « D’allié à ennemi. Stéréotypes et représentations du combattant russe dans les magazines illustrés français durant la Grande Guerre », Amnis, n 1710, (amnis.revues.org/1402).

CARÊME M.-A. 1815. Le pâtissier royal parisien ou Traité élémentaire et pratique de la pâtisserie ancienne et moderne, Paris, vol. 1.

Delvau A. 1883. Dictionnaire de la langue verte, Paris.

DotTin G. 1899. Glossaire des parlers du Bas-Maine (département de la Mayenne), Paris.

Dubosc G. « La moisson, les “aoûteux” », Journal de Rouen, 31 juillet 1898.

Dumas A. 2000. Grand dictionnaire de cuisine, Paris, Phébus.

ESNAULT G. 1919. Le poilu tel qu'il se parle : dictionnaire des termes populaires, récents et neufs, employés aux armées en 1914-1918, étudiés dans leur étymologie, leur développement et leur usage, Paris, Bossard.

KaвAKova G. I. 2013. L'hospitalité, le repas, le mangeur dans la civilisation russe, Paris, L'Harmattan.

KRAUSS Ch. 2007. La Russie et les Russes dans la fiction française du XIX'e siècle (18121917), Amsterdam - New York, Rodopi.

Ledieu A. 1893. Petit glossaire du patois de Démuin, Paris, Alphonse Picard.

Mollard-Desfour A. 2012. Le vert. Dictionnaire de la couleur, mots et expressions d'aujourd'hui : XX'-XXI', Paris, CNRS Éditions.

Morelot S. 1800. Cours élémentaire d'histoire naturelle pharmaceutique, Paris, t. 2.

Perret P. 2002. Le parler des métiers, Paris, Robert Laffont.

Perrier-Robert A. 2012. Dictionnaire de la gourmandise, Paris, Robert Laffont, «Bouquins ». 
PicQuenard G.-A. 1910. « Le parler populaire de Quimper », Annales de Bretagne, vol. $26, \mathrm{n}^{\circ} 4$, p. $758-769$.

Rigaud L. 1888. Dictionnaire d'argot moderne. Nouvelle édition, Paris, P. Ollendorff.

SAINEANU L. 1925. Les sources indigènes de l'étymologie française, vol. 1, Nouvelles perspectives, Paris, É. de Boccard.

Tabouis G., Mousset A. 1951. Paris sous l'ennemi de César à Bismarck, Paris, Nouvelles Latines.

VERRIER A. J., ONILlON R. 1908. Glossaire étymologique et historique des patois et des parlers de l'Anjou : comprenant le glossaire proprement dit des dialogues, contes, récits et nouvelles en patois, le folklore de la province, Angers, Germain et G. Grassin, vol. 2.

VIRMAîTRE Ch. 1894. Dictionnaire d'argot fin-de-siècle, Paris, A. Charles. 